\title{
An investigation and analysis of the activities of daily living of older adults living at home in Ningxia Hui Autonomous Region of China: a cross-sectional study
}

Xiaofeng $\mathrm{Xu}^{1}$, Lina Yang ${ }^{2}$, Xiaohui Miao ${ }^{3}$ and Xiuying $\mathrm{Hu}^{4^{*}}$

\begin{abstract}
Background: To investigate the current situation regarding the activities of daily living (ADL) of older adults living at home in Ningxia Hui Autonomous Region of China and to analyze the associated factors of ADL performance so that we can provide references for the implementation of pension policies and long-term care insurance of older adults living at home.

Methods: We surveyed a total of 1040 older adults who live at home and receive home-based care in Ningxia Hui Autonomous Region by a face-to-face evaluation. A logistic regression model was used to analyze the factors associated with ADL performance.

Results: In the study, $82.79 \%$ of the older adults living at home can live independently. A total of $11.92 \%$ of the older adults have mild dysfunction, $4.33 \%$ have moderate dysfunction, and $0.96 \%$ have severe dysfunction. Multiple logistic analyses indicated that older adults with very difficult economic conditions (OR 3.212; 95\% Cl(1.209-8.534)) and without a spouse (OR 1.616; 95\% Cl(1.098-2.377)) were significantly associated with ADL limitations. In addition, the risks of ADL limitations in older adults aged 60-69 years and 70-79years were 0.187 and 0.4307 times, respectively, that of older adults over 80 years old. The risk of ADL limitations in older adults of the Han nationality was 0.605 times that of the minority population. More highly educated and older adults without diseases have a lower risk of $\mathrm{ADL}$ limitations.

Conclusions: Compared with the national average in China, the number of ADL limitations of older adults in Ningxia is greater and is associated with advanced age, ethnic minority status, low education level, low income, lacking a spouse and having diseases. As the number of older adults increases, maintaining and improving their ability to perform ADL and providing comfortable pension services and health services urgently need to be solved.
\end{abstract}

Keywords: Older adults, Living at home, Activities of daily living, Pension policy

* Correspondence: 2016224020202@stuscueducn

${ }^{4}$ Innovation Center of Nursing Research, West China School of Medicine/

West China Hospital, Sichuan University, Chengdu 610041, China

Full list of author information is available at the end of the article

C C The Author(s). 2020 Open Access This article is licensed under a Creative Commons Attribution 4.0 International License, which permits use, sharing, adaptation, distribution and reproduction in any medium or format, as long as you give appropriate credit to the original author(s) and the source, provide a link to the Creative Commons licence, and indicate if changes were made. The images or other third party material in this article are included in the article's Creative Commons licence, unless indicated otherwise in a credit line to the material. If material is not included in the article's Creative Commons licence and your intended use is not permitted by statutory regulation or exceeds the permitted use, you will need to obtain permission directly from the copyright holder. To view a copy of this licence, visit http://creativecommons.org/licenses/by/4.0/. The Creative Commons Public Domain Dedication waiver (http://creativecommons.org/publicdomain/zero/1.0/) applies to the data made available in this article, unless otherwise stated in a credit line to the data. 


\section{Background}

Since 1999, when societal aging began in China, population aging has been progressing [1]. The issues associated with population aging are also progressing. By the end of 2018, the number of older adults over the age of 60 in China reached 249.49 million, accounting for $17.9 \%$ of the total population [2]. The number of older adults is continuing to increase. The traditional and prevalent Chinese pension service is home-based care [3]. Home-based care is administered to older adults living in their own homes rather than in institutions [4]. The home-based care in China is similar to the community pension services in developed countries such as the United Kingdom. Community pension services take care of older adults in the community by professional staff or family, friends, neighbors, and community volunteers while using community resources [5]. However, compared with community pension services, home-based care in China often lacks mature community-supporting facilities, especially in remote areas with poor economic conditions and poor medical resources [3]. In areas with poor economic conditions and poor medical resources, such as the Ningxia Hui Autonomous Region of China, most of the young people work outside of the area. Their parents can only live alone or live with their spouses. Many older adults living in rural or remote areas do not have pension insurance [6]. Once they lose the activities of daily living (ADL), they will bring heavy care and economic burdens to their families. Therefore, the inability of older adults to perform ADL is particularly prominent. ADL comprise basic activities necessary for people to take care of themselves, maintain personal hygiene and carry out independent social activities in their daily lives, which are the most basic and common activities [7].

At the end of 2015, the number of disabled and semidisabled older adults in China was approximately 40.63 million, accounting for $18.3 \%$ of the older adults [8]. Long-term care for older adults who are disabled has become increasingly more important [9]. Facing the needs of a large number of disabled people for long-term care guarantees, the long-term care insurance system came into being in China. In 2016, 15 cities and two provinces (Shandong Province and Jilin Province) in China launched a pilot long-term care insurance system, focusing on solving the costs of basic living care and medical care for severely disabled people [10]. Ningxia Hui Autonomous Region currently has no pilot program for long-term care insurance. Therefore, disabled people, especially disabled older adults, still cannot enjoy longterm care insurance treatment.

According to the data, at the end of 2018, among the permanent residents of the Ningxia Hui Autonomous Region of China, there were 945,500 people aged 60 and over, accounting for $13.74 \%$ of the permanent resident population [11]. By the end of 2017, the size of the population aged 60 and over increased by 49,600 , increasing the proportion of the older population by $0.6 \%$ [11]. As a minority autonomous region, Ningxia has unique characteristics. For example, ethnic minorities constitute $1 / 3$ of the population of the region [12]. With the increasing number of older adults in Ningxia, the inability of older adults living at home to perform ADL during the day is also a prominent issue. With the continuous expansion of the scope of the pilot long-term care insurance, the pilot will be conducted in the Ningxia Hui Autonomous Region in the future. Then, investigating the ADL performance of older adults in the region and its associated factors can provide a reference for future long-term care insurance trials.

According to the World Health Organization (WHO), the ability to perform ADL is an essential indicator for the health status of older adults [13]. In addition, many studies have shown that older adults who lack ADL have a high psychological burden and a high risk for mortality [14]. Influenced by traditional Chinese concepts and cultural consciousness, home-based care has become the preferred way for older adults [15]. Therefore, when older adults cannot take care of themselves, there is a significant increase in the burden on families and caregivers [16]. Government and social support forces must intervene to care for older adults who cannot take care of themselves. However, before these interventions occur, it is necessary to investigate the ability of older adults to perform ADL in Ningxia. By analyzing the associated factors of ADL in older adults in Ningxia, we can provide a reference for the government to develop a better pension policy and to implement long-term care insurance. We can also provide some references to other developing countries and multiethnic countries like Ningxia Hui Autonomous Region of China on pensions.

\section{Methods \\ Study design and survey tool}

We consulted doctors, nurses, rehabilitators, dietitians, and other experts in fields related to aging before conducting the cross-sectional investigation. We decided to use the Barthel index (BI) as the assessment tool for this study. The BI is currently recognized worldwide as a tool for evaluating the ability of individuals to independently perform ADL. It was designed by Mahoney and Barthel in the mid-1950s [17]. The BI is a tool with excellent reliability and validity. The kappa values corresponding to the testretest reliability and the split-half reliability are between -1 and 1 , and that of the split-half reliability is 0.903. The Cronbach's alpha coefficient is 0.916. In addition, the Kaiser-Meyer-Olkin (KMO) statistic is 0.85 [18]. 
The BI consists of 10 items (feeding, bathing, grooming, dressing, bowel controlling, bladder controlling, toilet using, bed and chair transferring, mobility on level surfaces, stair climbing), and each item corresponds to three response options: full dependency, need help, and complete independence [19]. The total score can reach 100 points. The lower the score is, the higher the dependency of the individual. An overall score of 100 means that the respondent can take care of himself or herself and does not need help. An overall score of 60 to 99 indicates that the respondent has mild dysfunction and can complete some of the daily activities independently but that he or she needs some help. A total score of 41 to 59 points means that the respondent has moderate dysfunction and needs help completing daily activities. An overall score of fewer than 40 means that the respondent has severe dysfunction and that he or she cannot complete most ADL without help [20].

\section{Sampling}

The required sample size was 700 to 1000 older adults according to the following formula: $n=z^{2} p(1-p) /\left\{e^{2}+z^{2}\right.$ $p(1-p) / \mathrm{N}\}(z=1.96 ; P$ represents the estimated value of the overall proportion; in this study, $\mathrm{p}$ represents the proportion of the older adults in the total population, i.e., $p=0.179$; $e$ is the allowable error limit and $e=0.03$; $\mathrm{N}$ represents the number of older adults in China) [21]. This study is a cross-sectional survey. In addition, the sampling methods included stratified sampling, convenience sampling, and quota sampling. Stratified sampling involved categorizing each community health service center in a certain area as one of three types of communities: an urban community, an urban-rural integrated community, or a rural community. The convenience sampling method was used to extract communities and residents. In particular, 235 to 335 older adults were selected from each community for investigation. When the older adults were sampled with the convenience sampling method, $10 \%$ of the 235 to 335 older adults were required to be over 80 years old to achieve the purpose of quota sampling.

The inclusion criteria of the surveyed population included people who were 60 years old or over 60 years old and lived at home. The older adults included in the study could communicate without barriers after visual and auditory correction, provided informed consent and voluntarily participated in the survey. Older adults who had a mental illness, substance addiction, obvious memory or cognitive impairment, obvious hearing impairment, or language communication impairment and those who were unwilling to cooperate with the investigator were excluded.

\section{Data collection}

The investigator conducted a face-to-face evaluation, and the respondent provided answers. The investigators were trained with the same protocol before the investigation, and the investigations were conducted at a time at which the respondents were not busy to achieve quality control. From September to December 2018, we surveyed a total of 1062 older adults, and 1040 valid questionnaires were returned, for a response rate of $97.9 \%$.

\section{Statistical analysis}

After the questionnaires were retrieved, we used an Excel table for preliminary data collation. Then, SPSS19.0 statistical software was used for the chisquared test, rank-sum test, and logistic regression analysis. In the logistic regression analysis, missing values were 0 . We assigned each independent variable (such as $60-69$ years old $=1,70-79$ years old $=2, \geq 80$ years old $=$ 3 ) and added it to the logistic regression model and assigned dependent variables (live independently $=0$, dysfunction $=1) . P<0.05$ means the difference was statistically significant.

\section{Results}

Sociodemographic characteristics of the respondents and their ADL performance

The average age of the 1040 older adults living at home was 70.48 years, and there were 129 people over 80 years old. A total of $82.79 \%$ (861 older adults) of the older adults in the study living at home could live independently (older adults had no ADL limitations). A total of $11.92 \%$ (124 older adults) of the older adults had mild dysfunction, $4.33 \%$ (45 older adults) had moderate dysfunction, and $0.96 \%$ (10 older adults) had severe dysfunction. The older adults who were younger had better ADL abilities than those who were older. The older adults with Han nationality had better ADL abilities than those without Han nationality. The older adults who did not have religious beliefs (i.e., believed in a religion such as Christianity, Buddhism or Islam) had better ADL abilities than those who did have religious beliefs. The older adults with a high level of education had better ADL abilities than those with a low level of education. The older adults who had a spouse had better ADL abilities than those who did not have a spouse. The older adults with good economic status had better ADL abilities than those with poor economic status. In addition, the older adults with diseases had better ADL abilities than those without diseases. The difference was statistically significant $(P<0.05)$ (Table 1$)$. 
Table 1 The ADL performance in older adults living in Ningxia Hui Autonomous Region

\begin{tabular}{|c|c|c|c|c|c|c|c|c|}
\hline & & $\begin{array}{l}\text { Number of } \\
\text { people }\end{array}$ & $\begin{array}{l}\text { Severe } \\
\text { dysfunction } \\
\mathrm{N}(\%)\end{array}$ & $\begin{array}{l}\text { Moderate } \\
\text { dysfunction } \\
\mathrm{N}(\%)\end{array}$ & $\begin{array}{l}\text { Mild dysfunction } \\
\mathrm{N}(\%)\end{array}$ & $\begin{array}{l}\text { Live } \\
\text { independently } \\
\mathrm{N}(\%)\end{array}$ & $x^{2} / z$ & $P$ \\
\hline \multirow[t]{3}{*}{ Age $^{\#}$ (years) } & $60 \sim 69$ & 505 (48.56\%) & $1(0.20 \%)$ & $13(2.57 \%)$ & 43 (8.51\%) & 448 (88.71\%) & 54.300 & $<0.001$ \\
\hline & $70 \sim 79$ & 406 (39.04\%) & $6(1.48 \%)$ & 16 (3.94\%) & 49 (12.07\%) & 335 (82.51\%) & & \\
\hline & $\geq 80$ & $129(12.40 \%)$ & $3(2.33 \%)$ & $16(12.40 \%)$ & 32 (24.81\%) & $78(60.47 \%)$ & & \\
\hline \multirow[t]{2}{*}{ Sex* } & Male & 527 (50.67\%) & $5(0.95 \%)$ & $18(3.42 \%)$ & $61(11.57 \%)$ & $443(84.06 \%)$ & -1.169 & 0.242 \\
\hline & Female & $513(49.33 \%)$ & $5(0.97 \%)$ & 27 (5.26\%) & $63(12.28 \%)$ & 418 (81.48\%) & & \\
\hline \multirow[t]{2}{*}{ Ethnicity* ${ }^{*}$} & Han nationality & 854 (82.12\%) & $6(0.70 \%)$ & 25 (2.93\%) & 98 (11.48\%) & 725 (84.89\%) & -4.152 & $<0.001$ \\
\hline & minority & $186(17.88 \%)$ & $4(2.15 \%)$ & $20(10.75 \%)$ & $26(13.98 \%)$ & $136(73.12 \%)$ & & \\
\hline \multirow[t]{2}{*}{ Religious beliefs * (2) } & none & $542(52.12 \%)$ & $4(0.74 \%)$ & $16(2.95 \%)$ & 61 (11.25\%) & 461 (85.06\%) & -2.146 & 0.032 \\
\hline & have & 498 (47.88\%) & $6(1.20 \%)$ & 29 (5.82\%) & $63(12.65 \%)$ & $400(80.32 \%)$ & & \\
\hline \multirow[t]{6}{*}{ Educational level" } & illiteracy & 299 (28.75\%) & $6(2.01 \%)$ & $18(6.02 \%)$ & $32(10.70 \%)$ & 243 (81.27\%) & 31.895 & 0.007 \\
\hline & primary school & $303(29.13 \%)$ & $2(0.66 \%)$ & $12(3.96 \%)$ & $36(11.88 \%)$ & $253(83.50 \%)$ & & \\
\hline & junior high school & 189 (18.17\%) & $1(0.53 \%)$ & $5(2.65 \%)$ & 19 (10.05\%) & 164 (86.77\%) & & \\
\hline & $\begin{array}{l}\text { Secondary or high } \\
\text { school }\end{array}$ & $108(10.38 \%)$ & $1(0.93 \%)$ & $3(2.78 \%)$ & $13(12.04 \%)$ & $91(84.26 \%)$ & & \\
\hline & $\begin{array}{l}\text { College or } \\
\text { undergraduate }\end{array}$ & 124 (11.92\%) & $0(0.00 \%)$ & $3(2.42 \%)$ & $20(16.13 \%)$ & $101(81.45 \%)$ & & \\
\hline & $\begin{array}{l}\text { Postgraduate or } \\
\text { above }\end{array}$ & $17(1.63 \%)$ & $0(0.00 \%)$ & $4(23.53 \%)$ & $4(23.53 \%)$ & 9 (52.94\%) & & \\
\hline \multirow[t]{2}{*}{ With a spouse* (3) } & no & 237 (22.79\%) & $2(0.84 \%)$ & $20(8.44 \%)$ & 39 (16.46\%) & $176(74.26 \%)$ & -4.029 & $<0.001$ \\
\hline & yes & 803 (77.21\%) & $8(1.00 \%)$ & $25(3.11 \%)$ & 85 (10.59\%) & 685 (85.31\%) & & \\
\hline \multirow[t]{2}{*}{ Way of living*๑ } & Living alone & $48(4.62 \%)$ & $2(4.17 \%)$ & $3(6.25 \%)$ & $4(8.33 \%)$ & $39(81.25 \%)$ & -0.421 & 0.674 \\
\hline & Living with family & 755 (72.60\%) & $6(0.79 \%)$ & 22 (2.91\%) & 81 (10.73\%) & 646 (85.56\%) & & \\
\hline \multirow[t]{5}{*}{ Economic situation \# () } & Very difficult & $42(4.04 \%)$ & $1(2.38 \%)$ & $5(11.90 \%)$ & $8(19.05 \%)$ & $28(66.67 \%)$ & 43.958 & $<0.001$ \\
\hline & Slightly difficult & 274 (26.35\%) & $5(1.82 \%)$ & $21(7.66 \%)$ & 43 (15.69\%) & 205 (74.82\%) & & \\
\hline & Moderate & 443 (42.60\%) & $4(0.90 \%)$ & $7(1.58 \%)$ & 48 (10.84\%) & 384 (86.68\%) & & \\
\hline & Slightly favorable & 201 (19.33\%) & $0(.00 \%)$ & $5(2.49 \%)$ & 18 (8.96\%) & 178 (88.56\%) & & \\
\hline & Favorable & 80 (7.69\%) & $0(0.00 \%)$ & 7 (8.75\%) & 7 (8.75\%) & $66(82.50 \%)$ & & \\
\hline \multirow[t]{2}{*}{ Medical insurance* ๑ } & none & 71 (6.83\%) & $0(0.00 \%)$ & $3(4.23 \%)$ & $5(7.04 \%)$ & $63(88.73 \%)$ & -1.348 & 0.178 \\
\hline & have & 969 (93.17\%) & $10(1.03 \%)$ & $42(4.33 \%)$ & $119(12.28 \%)$ & 798 (82.35\%) & & \\
\hline \multirow[t]{4}{*}{ Body Mass Index* (BMI) $\odot$} & $<18.5$ & $31(2.98 \%)$ & $0(0.00 \%)$ & $4(12.90 \%)$ & $5(16.13 \%)$ & $22(70.97 \%)$ & 10.810 & 0.289 \\
\hline & $18.5-23.9$ & 603 (57.98\%) & $7(1.16 \%)$ & $20(3.32 \%)$ & $70(11.61 \%)$ & 506 (83.91\%) & & \\
\hline & $24-27.9$ & $338(32.50 \%)$ & $3(0.89 \%)$ & 19 (5.62\%) & $40(11.83 \%)$ & $276(81.66 \%)$ & & \\
\hline & $\geq 28$ & $68(6.54 \%)$ & $0(0.00 \%)$ & $2(2.94 \%)$ & $9(13.24 \%)$ & $57(83.82 \%)$ & & \\
\hline \multirow[t]{2}{*}{ Diseases * (8) } & none & $104(10.00 \%)$ & $2(1.92 \%)$ & $8(7.69 \%)$ & $22(21.25 \%)$ & $72(69.23 \%)$ & -3.855 & $<0.001$ \\
\hline & have & 936 (90.00\%) & $8(0.85 \%)$ & 37 (3.95\%) & $102(10.90 \%)$ & 789 (84.29\%) & & \\
\hline
\end{tabular}

Note: * indicates the use of the rank-sum test; \# indicates the use of the chi-squared test

(1) the fact or state of belonging to a social group that has a common national or cultural tradition;(2)the person believes in a religion such as Christianity, Buddhism or Islam; (3)does the older adult currently have a spouse; (4) whether the older adult lives with others; (5)balance of family members' income and expenditure; (6Does the older adult have medical insurance; (7) weight-to-height ratio, calculated by dividing one's weight in kilograms by the square of one's height in meters and used as an indicator of obesity and underweight; (8)whether the older adults have a disease

The factors associated with ADL performance in older adults in the Ningxia region

Factors that may be associated with older adults' ability to perform ADL in Ningxia, such as a person's age, ethnicity, religious beliefs, educational level, marriage status, and economic situation and whether he or she has a disease, were treated as independent variables. We conducted multivariate logistic binary regression analysis with ability to perform ADL as the dependent variable. The results showed that the factors associating with ADL performance in older adults living in Ningxia included one's age, ethnicity, educational level, economic 
situation, marriage status, and whether the older adult had a disease (Table 2). The risks of ADL limitations in older adults aged 60-69 years and 70-79years were 0.187 and 0.4307 times that of older adults over 80 years old. The risk of ADL limitations in the older adults of the Han nationality was 0.605 times that of the minority population. The risks of ADL limitations in the older adults who completed primary school, junior high school, secondary school or high school, junior college or undergraduate education, and postgraduate education or above were $0.142,0.128,0.122,0.158$, and 0.241 times that of the illiterate older adults, respectively. The risk of ADL limitations in older adults with very difficult and slightly difficult economic conditions were 3.212 and 2.191 times that of the economically wealthy older adults, respectively. The risk of ADL limitations in older adults without a spouse was 1.616 times that of older adults with a spouse. The risk of ADL limitations in older adults without a disease living at home was 0.409 times that of older adults with diseases.

\section{Discussion}

This study shows that there are 861 people $(82.79 \%)$ living at home who can live independently in Ningxia, China. In addition, there are 179 people (17.21\%) who are completely or partially unable to live independently. According to a survey on ADL abilities in older adults living in other regions of China, $8 \%$ of the older adults living in Guangdong, Shanghai, Shanxi, Hubei, and Heilongjiang provinces cannot live independently [22]. A study investigating the ADL abilities of older adults living in Beijing, China found that $87.9 \%$ of them can live

Table 2 Multiple logistic regression analysis of factors associated with ADL limitations in older adults in the Ningxia Hui Autonomous Region

\begin{tabular}{|c|c|c|c|c|c|c|}
\hline Variable & $b$ & Standard error & Wals $X^{2}$ & $P$ & $O R$ & $95 \% \mathrm{Cl}$ \\
\hline \multicolumn{7}{|l|}{ Age (years) } \\
\hline$\geq 80$ & & & & & 1 (reference) & \\
\hline $60 \sim 69$ & -1.674 & 0.245 & 46.753 & $<0.001$ & 0.187 & $(0.116-0.303)$ \\
\hline $70 \sim 79$ & -1.180 & 0.238 & 24.695 & $<0.001$ & 0.307 & $(0.193-0.489)$ \\
\hline \multicolumn{7}{|l|}{ ethnic } \\
\hline minority & & & & & 1 (reference) & \\
\hline Han nationality & -0.503 & 0.228 & 4.858 & 0.028 & 0.605 & $(0.386-0.946)$ \\
\hline \multicolumn{7}{|l|}{ Religious beliefs } \\
\hline have & & & & & 1 (reference) & \\
\hline none & -0.134 & 0.201 & 0.445 & 0.505 & 0.874 & $(0.589-1.297)$ \\
\hline \multicolumn{7}{|l|}{ Educational level } \\
\hline Illiteracy & & & & & 1 (reference) & \\
\hline Primary school & -0.945 & 0.588 & 11.046 & 0.001 & 0.142 & $(0.045-0.449)$ \\
\hline Junior high school & -2.052 & 0.593 & 11.959 & 0.001 & 0.128 & $(0.040-0.411)$ \\
\hline Secondary or high school & -2.105 & 0.613 & 11.790 & 0.001 & 0.122 & $(0.037-0.405)$ \\
\hline College or undergraduate & -1.846 & 0.631 & 8.546 & 0.003 & 0.158 & $(0.046-0.544)$ \\
\hline Postgraduate or above & -1.422 & 0.599 & 5.628 & 0.018 & 0.241 & $(0.074-0.781)$ \\
\hline \multicolumn{7}{|l|}{ Economic situation } \\
\hline Abundant & & & & & 1 (reference) & \\
\hline Very difficult & 1.167 & 0.499 & 5.476 & 0.019 & 3.212 & $(1.209-8.534)$ \\
\hline Slightly difficult & 0.784 & 0.388 & 4.086 & 0.043 & 2.191 & $(1.024-4.688)$ \\
\hline Moderate & -0.021 & 0.380 & 0.003 & 0.955 & 0.979 & $(0.465-2.060)$ \\
\hline Slightly favorable & -0.281 & 0.410 & 0.470 & 0.493 & 0.755 & $(0.338-1.686)$ \\
\hline \multicolumn{7}{|l|}{ With a spouse } \\
\hline yes & & & & & 1 (reference) & \\
\hline no & 0.480 & 0.197 & 5.926 & 0.015 & 1.616 & $(1.098-2.377)$ \\
\hline \multicolumn{7}{|l|}{ Diseases } \\
\hline have & & & & & 1 (reference) & \\
\hline None & -0.894 & 0.251 & 12.683 & $<0.001$ & 0.409 & $(0.250-0.669)$ \\
\hline
\end{tabular}


independently [23]. According to a survey conducted by the National Committee on aging, the number of older adults who live independently in urban areas in China is $85.40 \%$, and in rural areas, it is $79.00 \%$. Therefore, compared with the national average or that of other regions in China, the number of ADL limitations of older adults in Ningxia is greater [24]. At present, the aging population in Ningxia is increasing. At the end of 2018, the number of individuals aged 60 and over was 945,500, accounting for $13.74 \%$ of the total population [11]. With the increasing number of older adults and the impact of diseases, the number of disabled older adults will also increase, and the number of ADL limitations will continue to increase. This finding reminds us to address the level of ability to perform ADL by older adults, especially older adults living at home, and to address the daily needs of the disabled older adults. With the gradual increase of disabled older adults in Ningxia, the implementation of related disability insurance policies, such as long-term care insurance, can provide assistance to a large number of disabled older adults. The government should formulate assessment and judgment criteria for measuring the incapacity of older adults in Ningxia Hui Autonomous Region as soon as possible and formulate corresponding subsidy policies. Such policies could alleviate the huge economic and care burden brought by disabled older adults in Ningxia.

The factors associating with ADL performance in the older adults are complex. The individual's natural attributes, living environment, economic status, disease status, and injury status are the main factors affecting ADL performance in older adults [25]. The results of this study show that one's age, ethnicity, educational level, economic situation, marriage status, and whether one has a disease are all factors associating with their ability to perform ADL independently.

Several studies have shown that older adults' ability to perform ADL is negatively correlated with age. The older the individual is, the lower the ability to perform ADL. In addition, the rate of decline in the ability to perform ADL increases with age [26, 27]. The survey also found that the proportion of individuals over 80 years old with ADL difficulty was significantly higher than that of individuals who were 60-79 years old, and the difference was statistically significant $(P<0.001)$. With an increase in age, the functions of the older adults gradually decline, and problems associated with comorbidities also appear. The ability to perform ADL also decreases rapidly, and the proportion of individuals with disabilities increases. Therefore, age is associated with older adults' ability to perform ADLs. The pension policy, such as a long-term care insurance system, should focus on the disability of older adults, especially disability assessments and subsidies for older adults over 80 years old. For older adults over 80 years old, community workers should also conduct disability assessments and functional maintenance exercises on time. Once an individual becomes incapacitated, life care and financial subsidies should be carried out in time.

Ningxia Hui Autonomous Region is a place where many ethnic groups live together, including Han, Hui, Uygur, Dongxiang, Kazak, Salar, and Baoan individuals. This study found that ethnicity is associated with ADL performance in older adults. The ADL performance of members of the Han nationality is better than that of ethnic minorities, and the risk of ADL limitations in members of the Han nationality is much lower than that of ethnic minorities. This result is related to the living environment of ethnic minorities in Ningxia. Many ethnic minority older adults live in relatively remote or rural areas, and they do not have pension insurance [28]. They are unable to obtain good health care and endowment insurance. Insurance similar to the long-term care insurance system can provide basic protection for ethnic minority older adults when they are disabled. For older ethnic minorities, regular ADL performance assessments should become one of the works of community workers to provide them with timely help.

In addition, the level of education and economic status was also associated with the ADL performance of older adults living at home. The higher the level of education is, the better the ADL performance of the older adults. According to the results of this study, older adults who have received an education have a lower risk of ADL limitations than those who are illiterate. The risk of ADL disability is increasing among older adults with a low socioeconomic status. An older adult follow-up survey in Taiwan, China showed that there was a negative correlation between social class and ADL performance after controlling for the level of education [29]. The results of this study also show that the ADL performance of older adults with good economic conditions is significantly higher than that of older adults with poor economic conditions. It may be that well-educated and high-income older adults have a higher capacity and more resources to deal with a disability. In addition, they are less likely to be severely disabled than those with a low level of education and low income. Older adults with poor economic status are often lacking support from a social health care system or can obtain only limited medical resources. Therefore, for older adults with low income and education levels, the long-term care insurance system should provide more subsidies. After the disability assessment of older adults living at home, financial subsidies are provided according to the disability level and economic status of older adults.

The study also found that older adults with spouses have better ADL performance than those without 
spouses. Most older adults with spouses can support each other and help each other to achieve self-care. In this study, there were 789 older adults $(84.29 \%)$ who had a disease and could live independently, and only 72 people (69.23\%) were in good physical health and could live independently. Studies have found that chronic diseases, such as diabetes, cataracts, strokes, and bronchial diseases, are the leading causes of the decline in ADL in the older adults in China. Alzheimer's disease is also one of the severe diseases affecting the ADL performance of older adults [30]. The results of this study are inconsistent with the results of previous studies. It may be that more older adults with diseases than older adults without diseases participated in the survey. Therefore, we conducted a multivariate analysis. The results showed that the risk of ADL limitations in older adults with a disease was higher than that of those without the disease. This result is consistent with previous research conclusions. A variety of diseases leading to declines in sensory function, including vision, hearing, swallowing ability, or physical disabilities, in older adults can cause a severe decline in ADL performance, hindering older adults living at home from living independently. It is recommended that Ningxia accelerate the establishment of a long-term pension insurance system to include family members in paying caregivers to reduce the pension burden of the whole society [31].

\section{Limitations}

This study does have some limitations. Due to resource and time constraints, this study did not investigate the current status of ADL performance in older adults in all cities in Ningxia. Only three cities were selected for investigation. A more comprehensive survey will be conducted in future research to complement the findings of this study.

\section{Conclusion}

In this survey, compared with the national average in China, the number of ADL limitations of older adults in Ningxia is greater. Moreover, the factors associated with ADL performance are complex. Advanced age, ethnic minority status, low educational level, low income, lacking a spouse and having diseases are all associated with ADL limitations. With the acceleration of the aging process and the increasing number of older adults in Ningxia, how to maintain and improve ADL performance among older adults, especially older adults living at home, and how to provide comfortable pension services and health services urgently need to be solved.

\section{Abbreviations}

ADL: Activities of daily living; WHO: World health organization; BI: Barthel index; KMO: Kaiser-meyer-olkin

\section{Acknowledgements}

Not applicable.

\section{Authors' contributions}

Conception and design: XFX and XYH. Data Analysis: XFX and XHM. Interpretation of the data: XFX, LNY, XHM. Writing of the manuscript: XFX and $\mathrm{XYH}$. All authors read and approved the final manuscript.

\section{Funding}

This study was supported by the Department of Science and Technology Research Projects of the Sichuan Province of China (Grant No.2018SZ0404). The funding body helped design the study, collect the data and write the manuscript.

This study was also supported by the Graduate Student's Research and Innovation Fund of Sichuan University (Grant No.2018YJSY103). The funding body helped analyze and interpret the data.

\section{Availability of data and materials}

The datasets used or analyzed during the current study are available from the corresponding author upon reasonable request.

\section{Ethics approval and consent to participate}

Verbal consent was obtained instead of written consent. In addition, this study was approved by the Chinese Nursing Association (CNA) (ZHKY201406).

\section{Consent for publication}

Not applicable.

\section{Competing interests}

The authors declare that they have no competing interests.

\section{Author details}

${ }^{1}$ The Trauma Center Ward 2 of West China Hospital/West China School of Nursing, Sichuan University, Chengdu 610041, China. ${ }^{2}$ Nursing department of the First People's Hospital of Yinchuan, Yinchuan, China. ${ }^{3}$ West China School of Nursing, Sichuan University, Chengdu, China. ${ }^{4}$ Innovation Center of Nursing Research, West China School of Medicine/West China Hospital, Sichuan University, Chengdu 610041, China.

Received: 8 October 2019 Accepted: 10 September 2020

Published online: 25 September 2020

\section{References}

1. Lu H. The influence of aging population on China's economy in the information society// IEEE international conference on Information Management \& Engineering. 2010. https://doi.org/10.1109/ICIME.2010. 5478053.

2. Li XY. The general trend of China's medical care integration: community home care. Chin J Geriatrics Res (Electronic Edition). 2019;6(3):1-3. https:// doi.org/10.3877/cma.j.issn.2095-8757.2019.03.001

3. Guo JC. International comparison and reference on home pension service mode. Soc Secur Stud. 2010;(1):29-39. https://doi.org/10.3969/j.issn.16744802.2010.01.005.

4. Yang ZC. Home-based care and chinese pension model. Econ Rev. 2000;(3): 60-61+69 https://doi.org/CNKI:SUN:JJPL.0.2000-03-012.

5. Yang BL. Community care in the UK: a new model of older adults care. Exploration Free Views. 2000;(12):42-4 https://doi.org/CNKI:SUN:JJPL.0.200003-012.

6. Jiang $Y$, Liang $Y H$, Shu YR. Investigation on the state of pension of minority older adults in remote areas. Laodong Baozhang Shijie 2017;(8):22, 24. https://doi.org/10.3969/j.issn.1007-7243.2017.08.015.

7. Katz, Sidney. Assessing self-maintenance: activities of daily living, mobility, and instrumental activities of daily living. J Am Geriatr Soc 1983;31(12):721727. https://doi.org/10.1111/j.1532-5415.1983.tb03391.x.

8. Tao T, Zhou Y, DAI LY, Chen WW, Yang ZP, Li YS. Guo ZY. Ma JX. Disability transition regularity in Chinese older persons:an analysis using a multistate Markov model. Chin Gen Pract. 2019;22(10):1165-1170. https://doi.org/10. 12114/j.issn.1007-9572.2019.10.007.

9. Wu LH. The Rescue Function of Social Health Insurance for the Disabled older adults_- Based on the Study of the Combination of Nursing Home 
and Home Health Care Applied to Long-term Care Model. J Fujian Norm Univ (Philosophy and Social Sciences Edition). 2014;(2):23-9. http://www. wanfangdata.com.cn/details/detail.do?_type=perio\&id=fjsfdxxb-Zx201402 004.

10. Deng J, Deng WY. A comparative analysis on financing arrangement of the first batch of long-term care insurance in pilot cities. Chin J Health Policy 2017;10(8):13-17. https://doi.org/10.3969/j.issn.1674-2982.2017.08.003.

11. China Business Research Institute. Analysis of Ningxia's population data in 2018: the resident population increased by 63,200 aging (the accompanying table). https:/s.askci.com/news/hongguan/20190214/1742171141605.shtml. Accessed 12 May 2020.

12. Li WW. Research on the path of poverty reduction in Ningxia rual areas from the perspective of human resource develpment. Ningxia Univ. 2018;1: 24 https://doi.org/CNKI:CDMD:2.1018.313279.

13. Wiener J M. Measuring the activities of daily living among the older adults: a guide to National Surveys. Pers Relat 2007;19(4):663-679. https://doi.org/ 10.1111/j.1475-6811.2011.01382.x

14. Jiao KS. The Relationship between Activities of Daily Living and Death Risk in the older adults in China. Med Philos. 2009;30(7):33-5. https://doi.org/ CNKI:SUN:YXZX.0.2009-07-016.

15. Yin $H R$, Yuan $H$, Shi XQ Li WT, An LB. The dilemma and countermeasures of the development of Chinese pension organizations under the background of deep aging. Chin J Gerontol 2016;36(13):3345-3347. https://doi.org/10. 3969/j.issn.1005-9202.2016.13.122.

16. Li P, Jiang $L P$, Chen YY, Qin QD. Family burden and its influencing factors of long term care for disabled older adults. Chin Nurs Res. 2016;30(21):25842587. https://doi.org/10.3969/j.issn.1009-6493.2016.21.008.

17. FJ Mahoney, DW Barthel. Functional evalution: The Barthel Index. Md Med J. 1965;14:61. https://www.researchgate.net/publication/266081168_ functional_evalution_the_barthel_index.

18. Hou DZ, Zhang Y, Wu JL, Li Y, An ZP. Study on reliability and validity of Chinese version of Barthel index. Clin Focus 2012; 27(3): 219-221. https:// doi.org/10.3760/cma.j.jissn.0254-1424.2012.05.013.

19. Lübke N, Meinck M, Von R W. The Barthel index in geriatrics. A context analysis for the Hamburg classification manual. Z Gerontol Geriatr 2004; 37(4):316-326. https://doi.org/10.1007/s00391-004-0233-2.

20. Lee YC, Chen SS, Koh CL, Hsueh IP, Yao KP, Hsieh CL. Development of two barthel index-based supplementary scales for patients with stroke. Plos One. 2014;9(10):e110494-. https://doi.org/10.1371/journal.pone.0110494.

21. Xu XF, Chen $\mathrm{Q}, \mathrm{Hu} \mathrm{XY}$. Current situation and influencing factors of the activities of daily living of the older adults living at home in Chengdu. Chin J Mod Nurs 2018; 24(19):2267-2270. https://doi.org/10.3969/j.issn.1671-167X. 2018.03.011

22. Xia YB, Ma Y, Hu Z, Chen RL, Zhang DM. Analysis on ability of daily living and its influencing factors among the elderly from five provinces in China. J Nanjing Med Univ (Soc Sci). 2017;17(2):102-105. https://doi.org/10.7655/ NYDXBSS20170205.

23. Liu M,Wang JH,Yang SS,YaoY, Wang SS, He Y. Evaluation of activities of daily living and related factors in community older adults in urban and rural areas of Beijing. Chin J Epidemiol 2018;39(3):268-272. https://doi.org/10. 3760/cma.j.issn.0254-6450.2018.03.004.

24. Sun JJ, Shen D. The intention for the old-age support of the Chinese elderly and its differences between urban and rural elderly: a study based on the china longitudinal aging social survey. Popul Econ.2017;(2):11-20. https:// doi.org/10.3969/j.issn.1000-4149.2017.02.002.

25. Bürge $E$, von Gunten $A$, Berchtold A. Factors favoring a degradation or an improvement in activities of daily living (ADL) performance among nursing home (NH) residents: a survival analysis. Arch Gerontol Geriatr. 2013;56(1): 250-257. https://doi.org/10.1016/.archger.2012.09.001.

26. Wu XL, Liu J, Dong TY. Longitudinal dynamic analysis of Chinese Elderly's activities of daily living. Sci Res Aging. 2018;6(1):28-45 http://www.cnki.com. cn/Article/CJFDTotal-LLKX201801004.htm.

27. Chen F, Liu K. The activities of daily living of the older adults in the community and its influencing factors. Chin J Gerontol. 2015;35(16):46624664. https://doi.org/10.3969 /j. issn. 1005-9202. 2015. 16. 114.

28. Gu F. Problems and measures existing in the pension insurance work of urban and rural residents in Yinchuan. Labor Secur World. 2019;(11):17-8 https://doi.org/CNKl:SUN:LDBJ.0.2019-11-014.

29. Li CY, Wu SC, Wen SW. Longest held occupation in a lifetime and risk of disability in activities of daily living. Occup Environ Med, 2000,57(8): 550554. https://doi.org/10.1136/oem.57.8.550.
30. Qian JH, Cao PY, Wu K, Luo HQ, Ren XH. Investigation of effects of chronic Eiseases on activities of Eaily living abilities of the older adults in China. Chin Gen Pract 2016; 19(35): 4364-4369. https://doi.org/10.3969/j.issn.10079572.2016.35.015.

31. Meng HX. Analysis on the necessity of constructing the Chinese pension insurance system. Mod Bus Trade Ind 2017;(04):147-149. https://doi.org/10. 19311/j.cnki.1672G3198.2017.04.064.

\section{Publisher's Note}

Springer Nature remains neutral with regard to jurisdictional claims in published maps and institutional affiliations.
Ready to submit your research? Choose BMC and benefit from:

- fast, convenient online submission

- thorough peer review by experienced researchers in your field

- rapid publication on acceptance

- support for research data, including large and complex data types

- gold Open Access which fosters wider collaboration and increased citations

- maximum visibility for your research: over $100 \mathrm{M}$ website views per year

At BMC, research is always in progress.

Learn more biomedcentral.com/submissions 